\title{
¿Juegos de niñas y juegos de niños? la influencia de los estereotipos de género en la elección de juguetes
}

\section{Toys for girls and toys for boys? The influence of gender stereotypes in the choice of toys}

\author{
Nuria Álvarez Rodríguez, María Victoria Carrera-Fernández, Xosé Manuel Cid-Fernández \\ Universidade de Vigo,
}

\begin{abstract}
Resumen
Este trabajo se orienta al análisis de la influencia de los estereotipos de género en los intereses de niñas/os de $6^{\circ}$ de Educación Infantil. La investigación se llevó a cabo en un CEIP con un total de 24 alumnas/os. Se realizó un estudio cualitativo, poniendo en práctica dos actividades. Los resultados ponen de manifiesto que los juegos tradicionalmente considerados como masculinos son demandados tanto por niños como por niñas, mientras que los juguetes tradicionalmente considerados como femeninos solo son elegidos por las niñas. Las niñas demandan los juegos "neutros" más que los niños. Se destacan las implicaciones para una práctica coeducativa en las escuelas infantiles.

Palabras clave: Estereotipos de género; socialización de género; juguetes; educación infantil; coeducación.
\end{abstract}

\begin{abstract}
The aim of this work is to analyze the influence of gender stereotypes on the interests of children in 6th grade in Early Childhood Education. The research was carried out in a CEIP with a total of 24 students. A qualitative study was carried out, putting into practice two activities. The results show that toys traditionally considered as masculine are demanded by both boys and girls, whereas toys traditionally considered as feminine are only chosen by girls. Neutral toys are chosen by girls more than by boys. Implications for educational practice are discussed. Keywords: Gender stereotypes; gender socialization; toys; kindergarten; co-education.
\end{abstract}

\section{Introducción}

Podemos definir los estereotipos de género como un conjunto de creencias y estructuras socialmente compartidas que contienen el conocimiento y las ideas sobre distintos grupos sociales, en concreto hombres y mujeres, asociando características y emociones con cada grupo en particular. Así tal y como destacan Rosenkrantz, Vogel, Bee y Broverman (1968, p.287), los estereotipos de género son "creencias consensuadas sobre las diferentes características de hombres y mujeres en nuestra sociedad".
Dentro de los estereotipos de género podemos identificar los descriptivos, que determinan cómo "deben ser" hombres y mujeres en relación a las características intelectuales y de personalidad (rasgos), así como en relación a la apariencia física (estereotipos descriptivos corporales); y los prescriptivos, que establecen las conductas y ocupaciones que deben llevar a cabo hombres y mujeres (Lameiras, Carrera y Rodríguez, 2013; Rodríguez, Lameiras, Magalhaes y Carrera, 2010).

El proceso de socialización es radicalmente diferente para niños y niñas, de hecho, hasta el siglo XIX se consideraba que las mujeres eran inversas a los hombres y de ahí se justificaba su mayor imperfección; lo que supuestamente implicaba diferencias en el carácter y en el temperamento, y justificaba las diferencias de trato y educación. Tal y como se puede observar en la obra "El Emilio" de Rousseau en la que se propugna una educación diferencial para Sofía, orientada exclusivamente en satisfacer a Emilio, ser buena madre y esposa (Núñez, 1997).

Estos rasgos y características en función del sexo biológico, contribuyen a configurar identidades femeninas y masculinas, de modo que al hombre se le identifica como autónomo e independiente, mientras que a la mujer se la socializa bajo el imperativo categórico de "serás madre y te preocuparas por la vida y las relaciones (Levinton, 1999, p.176). En esta dicotomía se describe a los hombres desde la instrumentalidad-autonomía y a las mujeres desde la expresividad-dependencia (Rodríguez et al., 2010).

De este modo, a partir del sexo biológico niños y niñas son socializados diferencialmente a través de los diferentes agentes de socialización, que Teresa de Lauretis denominó "Tecnologías del género" (1987), entre los que destacan la escuela, la familia y los medios de comunicación. Y así, este proceso de socialización, habitualmente silenciado y negado socialmente, 
continúa operando sobre los cuerpos para construir identidades diferentes y desiguales.

En esta línea, los juguetes, constituyen potentes herramientas de socialización que contribuyen al desarrollo de la expresividad o feminidad en las niñas y a la instrumentalidad o masculinidad de los niños. Entre los primeros planteamientos acerca del juego y del juguete se encuentran fundamentos teóricos de la Pedagogía y la Psicología de la primera mitad del siglo XX. Desde la perspectiva psicoanalítica Erikson planteó que entre los cuatro y los cinco primeros años de vida, el niño y la niña practican los futuros roles sociales mediante juegos, disfraces, cuentos y juguetes (2004).

Así, junto con las películas y los cuentos, los juguetes se convierten en importantes instrumentos socializadores y educativos, transmisores de un determinado sistema de valores socioculturales, incluyendo el código de las normas de género (Williams y Best, 1990). De forma que, si se analizan los juegos y juguetes que son asociados al género femenino inconscientemente pensamos en muñecas y objetos relacionados con el mundo doméstico, mientras que si pensamos en juguetes que se identifican con la masculinidad nombraríamos todos los juegos de acción, aventura o estrategia. De esta manera los videojuegos, especialmente los relacionados con estas temáticas, están más vinculados con las preferencias lúdicas de los chicos que de las chicas, ya que reúnen los ingredientes que tradicionalmente están ligados al sexo masculino (Martínez y Vélez, 2009).

En definitiva y como destaca Carrera (2015) el juego y los juguetes son especialmente relevantes para la formación de nuestra identidad de género. A tal efecto es importante una mirada atenta a los juguetes que se publicitan y compran para niñas y niños: muñecas, cocinitas, barbies y sets de belleza para ellas; juegos bélicos o de deportes y coches para ellos. De modo que muchos de los juguetes que compramos para niños y niñas son sexistas y constituyen un potente lecho de estereotipos, roles y mitos sobre el que se construye la violencia.

\section{Método}

\section{Participantes}

Tal y como se ha destacado, el estudio se llevó a cabo en un aula de $6^{\circ}$ de Educación Infantil de un centro público de Educación Infantil y Primaria de la Comunidad Autónoma Gallega, participando un total de 24 alumnas/os (la clase en su integridad), de los cuales 12 son niños y 12 niñas, con una edad media de 5 años y tres meses y un rango de entre 5 años y 5 años y 11 meses. Pertenecientes a familias con un nivel social y económico medio-alto.

\section{Instrumentos}

Se llevaron a cabo dos actividades, la primera, titulada "Carta a los Reyes/Reinas Magos/as" consistía en dar a cada niño y niña un folio en blanco, así como diferentes lápices de colores y pedirles que dibujasen los juguetes que querían que les trajesen los Reyes Magos. A continuación, la investigadora fue recogiendo individualmente los dibujos, preguntándole a cada niño/a qué significaba cada uno de ellos.

La segunda actividad, titulada "¿Juegos de niñas y juegos de niños?", fue acompañada de una entrevista grupal. Para su desarrollo se elaboró una pequeña presentación en power-point donde se incluyeron diferentes imágenes de niños y niñas jugando con distintos juguetes, extraídas en su mayoría de catálogos de juguetes, tal y como se puede ver en la imagen algunas de ellas eran estereotipadas (por ejemplo: un niño jugando con un coche o con una pistola y una niña jugando con una cocinita o con una muñeca) y otras no (por ejemplo: un niño jugando con una cocinita o con una muñeca, y una niña jugando con una pelota o con una pistola)

El orden de presentación fue el siguiente: i) Niño jugando con coche; ii) niño jugando con cocinita y niña jugando con cocinita; iii) niña jugando con muñeca; iv) niño jugando con muñeca; v) niña jugando con pelota; y vi) niño jugando con pistola y niña jugando con pistola. Tras la presentación de cada una de las imágenes se hicieron las siguientes preguntas a los niños y niñas en grupo: i) ¿Solo los niños pueden jugar con los coches?, ¿por qué?; ii) ¿Los niños no pueden jugar a las cocinitas?, ¿por qué?; iii) ¿Solo las niñas pueden jugar a las muñecas?, ¿por qué?; iv) ¿Por qué los niños no pueden jugar a las muñecas?; v) ¿Pueden las niñas jugar con las pelotas?, ¿por qué?; y v) Sólo los niños pueden jugar con pistolas?, ¿por qué?

\section{Procedimiento}

Se contactó directamente con la dirección del centro planteándole el objetivo del estudio, la metodología del mismo y la importancia de su colaboración. Para ello se entregó un documento en el que se informaba por escrito de todo lo anterior y se garantizaba el anonimato y la confidencialidad de los datos, así como la finalidad estrictamente académica del estudio. Una vez que el centro aceptó colaborar, se nos asignó un aula de $6^{\circ}$ de Educación Infantil. Concretamente, la actividad que aquí se presenta se llevó a cabo en horario lectivo en diciembre de 2013 en tres sesiones de tres horas de duración.

En cuanto al registro de los datos, al tratarse de niños y niñas de tan corta edad, para la información obtenida se utilizó la técnica de análisis de contenido, atendiendo al discurso simbólico y al discurso de carácter oral. Aunque la idea inicial era recoger los discursos a través de una grabación de audio, el centro no lo permitió, por lo que tuvimos que copiar literalmente las respuestas derivadas de las entrevistas grupales. Para facilitar el registro se pidió al alumnado que hablara despacio y respetando los turnos de palabra.

\section{Resultados}

En la primera actividad, "Carta a los Reyes/Reinas Mago/as, atendiendo a los resultados mostrados en la tabla 1 podemos ver que las niñas, del total de 35 juguetes que solicitan, piden siete que podríamos 
clasificar como tradicionalmente "masculinos" $(20 \%$ de los juguetes seleccionados), entre estos juguetes destacan algunos como "espadas" y "máquinas de videojuegos". Junto con quince (43\% de los juguetes seleccionados) que podrían clasificarse como tradicionalmente "femeninos", tales como "muñecas", "Barbies", "casa de la Barbie", "armario de la Barbie", u "ositos de peluche"; y trece (correspondientes al 37\% restante) de carácter "neutro", tales como "tablets", "pelotas" o "piscinas".

En cuanto a los niños, del total de 31 juguetes demandados, ninguno de ellos podría clasificarse como "tradicionalmente femenino", solicitando 24 juguetes tradicionalmente "masculinos" (77.4\% de los juguetes que piden) y 7 juguetes "neutros" (22.6\%). Entre los primeros destacan una "moto", un "coche", un "castillo" o una "espada"; y entre los segundos un "cuento", un "libro" o "una pelota".

Con relación al porcentaje total de los juguetes solicitados por los niños y las niñas, un $47 \%$ son tradicionalmente "masculinos" (es decir 31 juguetes "masculinos"); un $22.7 \%$ (correspondiente a 15 juguetes), sólo demandados por las niñas, son tradicionalmente "femeninos"; finalmente un $30.3 \%$ son de tipo neutro (20 juguetes).

En la segunda actividad, "Juegos de niñas y juegos de niños?", observamos que tanto niños como niñas entienden mayoritariamente que los coches son juguetes tradicionalmente masculinos, tal y como se observa en los siguientes diálogos:

Investigadora: ¿Os acordáis del día que os pedí que me dibujaseis lo que queríais que os trajeran los Reyes Magos?

Niños y niñas: ;Siii! (contestan todos/as).

Investigadora: Bien, ahora os voy a enseñar una serie de juguetes en la pizarra digital (señalo la pizarra digital) y os voy hacer unas preguntas. Pero para hablar tenéis que levantar la mano (levanto la mano). ¿Vale?

Niños y niñas: ;Siii! (contestan todos/as).

Investigadora: A ver... ¿solo los niños pueden jugar con los coches? (mira a la pizarra digital para leer la pregunta)

Niños: ¡Siiii! (responden la mayoría de ellos/as)

Investigadora: ¿Por qué? (respondo extrañada)

Iván: Porque son para que jueguen los chicos (levanta la mano para hablar)

Diego: ¡Porque son de chicos!

Gonzalo: En la guardería de mi abuela tiene coches y juegan las niñas con ellos (levanta la mano para hablar).

Víctor: ¡Están hechos para que jueguen los niños!

(Líneas 191-205)

Otra de las preguntas presentadas, en relación a una imagen de un niño jugando con una cocinita fue: “ ¿Los niños no pueden jugar a las cocinitas?”. Las respuestas reflejan interesantes concepciones sobre los roles de género. Así, Iván señala que los niños solo pueden jugar a las cocinitas cuando están solos; en la misma línea
Rubén destaca que cuando un niño está solo puede cocinar y "poner la casa patas arriba", lo cual podría estar haciendo también referencia a que, cuando sean mayores y tengan pareja, solo cocinarán cuando su pareja (heterosexual) no esté. Además, vemos que niños y niñas distinguen entre diferentes tipos de cocina, las "rosas para las niñas" como señala Olga y las "rojas o normales" para los niños, como dice Diego:

Investigadora: Miramos esta foto (señalo en la pizarra digital y pregunto)... ¿Los niños no pueden jugar a las cocinitas?

Diego: ¡No! porque cuando seas mayor y no estés con nadie tienes que cocinar.

Iván: La cocina es juego para que juegues solo si estás en casa sólo.

Rubén: Cuando un niño está sólo puede cocinar y poner la casa patas arriba.

Olga: Las cocinas rosas son de chicas (Levanta la mano).

Diego: $Y$ las rojas o normales son para chicos. (Levanta la mano).

Cristina: ¡Las niñas siempre juegan a la cocina!

(Líneas 206-214)

A la pregunta “Solo las niñas pueden jugar a las muñecas?" La respuesta de los niños y de las niñas fue un sí muy rotundo destacando, entre sus argumentaciones que a los niños no les gustan las muñecas, aunque a veces jueguen con ellas:

Investigadora: ¿Solo las niñas pueden jugar a las muñecas?

Niños y niñas: ¡Siii! (exclaman todos/as)

Diego: ¡Es un juego de chicas!

Víctor: A los chicos no les gusta jugar con las muñecas

Daniela: ¡Las muñecas son para las chicas! (Levanta la mano)

Iván: A los niños no nos gustan las muñecas.

Investigadora: ¿Por qué los niños no pueden jugar a las muñecas?

Diego: Bueno a veces juagan los chicos Iván: ¡Ese juego siempre es más de chica!

(Líneas 216-223)

Por lo que respecta a las pelotas, parece que este juego es más neutro, no identificándolo tanto con un género u otro. No obstante, parece, tal y como señala Ana, que las pelotas de "Hello Kitty" solo son para las niñas:

Investigadora: ¿Pueden las niñas jugar con las pelotas?

Niños y niñas: ;Siii! (contestan todos los niños y niñas)

Nerea: A algunas niñas les gusta el futbol (Levanta la mano)

Tamara: Hay niñas que juegan al baloncesto

Gonzalo: A mí me gusta jugar al futbol

Rubén: ;Yo juego al futbol! 
María: Yo siempre juego al futbol porque me gusta Daniela: En mi casa tengo pelotas (Levanta la mano) Marta: Las pelotas las podemos botar

Ana: Pues yo tengo una pelota de Hello Kitty

(Líneas 224-233)

Y la última pregunta fue acerca de las pistolas (“¿Sólo los niños pueden jugar con pistolas?”) Las respuestas fueron bastante indicativas de que los juguetes de guerra no están prohibidos para las niñas, sino más bien legitimados:

Investigadora: ¿Sólo los niños pueden jugar con pistolas?

María: ¡Yo tengo una espada laser! (Levanta la mano)

Lorena: Son también para niñas, porque mi hermano tiene una y yo también.

Diego: A mí me trajeron los Reyes una.

Iván: Y a mí.

(Líneas 234-238)

\section{Discusión}

Los resultados derivados de las dos actividades ponen de manifiesto que la socialización diferencial de género tiene un fuerte impacto en la infancia y que la elección de juguetes está fuertemente influenciada por los estereotipos de la masculinidad y la feminidad. Además, si tenemos en cuenta que el juego tiene un fuerte carácter socializador (Martínez y Vélez, 2009) y que, por tanto, refuerza los estereotipos de género, nos daremos cuenta de que nos situamos ante una realidad educativa que dista mucho de ser igualitaria y que, tristemente, reproduce los estereotipos de género tradicionales, construcciones sociales que, sin embargo, son naturalizados dentro y fuera de la comunidad educativa (Lameiras et al., 2013). Asimismo, en la línea de los estudios disponibles, se observa que es más fácil para las niñas transgredir la norma de género que para los niños, lo cual no sorprende en una sociedad que sobrevalora la masculinidad hegemónica y que, por tanto, castiga duramente a aquellos niños/hombres que la rechazan para adscribirse a rasgos y roles asociados a la denostada feminidad tradicional (Bonilla y MartínezBenlloch, 2000; Lameiras et al., 2013).

Así, la escuela debe optar por un modelo educativo enmarcado en el paradigma socio-crítico de la educación. Para ello, es fundamental la presencia de un profesorado formado en estas cuestiones, consciente de que la tarea verdaderamente educativa, que por definición es coeducativa, va más allá de la pura instrucción y constituye necesariamente un proceso de humanización (Freire, 2001). Solo a través de una práctica verdaderamente coeducativa desde la infancia podremos modificar los estereotipos de género que se identifican desde los primeros años y que van marcándose a fuego en la construcción de la identidad de las personas, estereotipos que están en estrecha conexión con las actitudes sexistas, y que constituyen el lecho sobre el que descansa la violencia de género (Carrera, 2015).

\section{Referencias}

Bonilla, A. y Martínez-Benlloch, A.P. (2000). Identidades, transformación de modelos sociales y su incidencia en el ámbito educativo. En J. Fernández (Ed.), Intervención en los ámbitos de la sexología y de la generología (pp. 135-176). Madrid: Pirámide.

Carrera, M.V. (25 noviembre 2015). Las semillas de la violencia. Xornal Escolar, La Región, p.7.

Erikson, E. (1974). Identidad, juventud y crisis. Buenos Aires: Paidós.

Freire, P. (2001). Pedagogía de la indignación. Barcelona: Ariel.

Lameiras, M., Carrera, M.V. y Rodríguez, Y. (2013). Sexualidad y salud. El estudio de la sexualidad humana desde una perspectiva de género. Vigo: Servizo de Publicacións da Universidade de Vigo.

Lauretis, T. (1987). Technologies of Gender: essays in theory, film, and fiction. Bloomignton: Indiana University Press.

Martínez, M.C y Vélez, M. (2009). Actitud en niños y adultos sobre los estereotipos de género en juguetes infantiles. Ciencia Ergo Sum, 16, 137-144

Núñez, V. (1997). Sofía o la educación de la mujer. Revista de Pedagogía Social, 15-16, 49-67

Rodríguez, Y., Lameiras, M., Magalhães M.J. y Carrera, M.V. (2010). Los rasgos expresivos e instrumentales de la comunidad educativa española: estudiantes, padres/ madres y docentes. Summa Psicológica UST, 7(2), 75-82

Rosenkrantz, P., Vogel, S., Bee, H \& Broverman, D.M. (1968). Sex-role stereotypes and sef-concepts in college students. Journal of Consulting and Clinical Psychology, 32, 287-295.

Williams, J.L. y Best, D. L. (1990). Measuring sex stereotyping: a multination study. Newbury Park: Sage. 